\title{
Depoimento Especial, Testemunho Judicial, Diretrizes Internacionais: Dissonâncias
}

\author{
José César Coimbra ${ }^{1}$ \\ ${ }^{1}$ Pontifícia Universidade Católica do Rio de Janeiro, \\ RJ, Brasil.
Roberta Gomes Nunes ${ }^{2}$
${ }^{2}$ Universidade do Estado do Rio de Janeiro, \\ RJ, Brasil. \\ Cristiana de Faria Cordeiro ${ }^{3}$ \\ ${ }^{3}$ Tribunal de Justiça do Estado do Rio de Janeiro, \\ RJ, Brasil.
}

\begin{abstract}
Resumo: O depoimento especial de crianças e adolescentes e a Lei 13.431/2017 questionam a interface entre a psicologia e a justiça. Essa lei tem em suas fontes a Resolução 20/2005, do Conselho Econômico e Social das Nações Unidas, que traça diretrizes para a justiça em casos de crianças vítimas ou testemunhas de crime. Realizou-se pesquisa qualitativa, baseada em levantamento bibliográfico e documental, tendo por eixo as legislações mencionadas e os procedimentos e papéis profissionais nelas previstos. Avalia-se a dissonância entre os dois documentos e suas consequências, bem como as definições de vitimização secundária, revitimização, pessoa de apoio e intermediário, não adotadas na Lei 13.431/2017. Algumas práticas estrangeiras alinhadas à Resolução 20/2005 são descritas e comentadas, mostrando diferenças significativas em relação ao que é realizado no Brasil. Conclui-se que uma dessas diferenças entre um e outro documento é o aspecto da proteção, que perde sua força e revela $o$ limite do funcionamento do judiciário no acolhimento daquele que demanda cuidado.
\end{abstract}

Palavras-chave: Depoimento especial, Abuso da criança, Testemunhos, Processos legais.

\section{Special Testimony, Judicial Testimony, International Guidelines: Dissonances}

\begin{abstract}
The special testimony of children and adolescents and the Law 13431/17 question the interface between psychology and justice. This law results from the Resolution 20/2005 of the Economic and Social Council of the United Nations, which outlines guidelines for justice in matters involving child victims or witnesses of crime. Considering the aforementioned legislation and their provisions for procedures and professional roles, a qualitative research based on bibliographic and documentary surveys was conducted to evaluate the dissonances between the two documents and their consequences, as well as the definitions of secondary victimization, revictimization, support person, and mediator - not provided in the Law $13431 / 17$. This paper describes and comments some foreign practices aligned with the Resolution 20/2005, showing significant differences with the practices employed in the Brazilian scenario. The results indicate that the protection aspect loses its strength between one document and the other, revealing the limit of the judiciary functioning in hosting those who demand care.
\end{abstract}

Keywords: Special testimony, Child abuse, Testimonies, Legal processes. 


\title{
Declaración Especial, Testimonio Judicial, Directrices Internacionales: Disonancias
}

\begin{abstract}
Resumen: La declaración especial de niños y adolescentes y la Ley 13.431/2017 cuestionan la relación entre psicología y justicia. Esta ley tiene en sus fuentes la Resolución 20/2005, del Consejo Económico y Social de las Naciones Unidas, relativa a directrices sobre la justicia para los niños víctimas o testigos de delitos. Se realizó una investigación cualitativa, basada en levantamiento bibliográfico y documental, cuyos ejes fueron las mencionadas legislaciones y los procedimientos y roles profesionales previstos en ellas. Se evalúa la disonancia entre los dos documentos y sus consecuencias, así como las definiciones de victimización secundaria, re-victimización, persona de apoyo e intermediario, no adoptadas en la Ley 13.431/2017. Algunas prácticas extranjeras acorde a la Resolución 20/2005 se describen y comentan, subrayando diferencias significativas con lo que se realiza en Brasil. Se concluye que una de estas diferencias es la protección que pierde su fuerza y evidencia el límite del funcionamiento del sistema judicial en la protección de quien demanda cuidado.
\end{abstract}

Palabras clave: Declaración especial, Abuso del niño, Testimonios, Procesos legales.

O depoimento especial mostra-se tema renovado de atenção, com diferentes perspectivas lançadas sobre ele (Brito \& Pereira, 2012; Coimbra, 2014; Pelisoli \& Dell'Aglio, 2016; Pelisoli, Dobke, \& Dell'Aglio, 2014; Ramos, 2015; Santos \& Coimbra, 2017). O documentário (H)ouve? apresenta as aporias e os argumentos a favor e contra essa prática, deixando ver o quanto a discussão, a avaliação e a análise das justificativas e dos diversos protocolos associados a ela ainda são necessárias (Ramos \& Ligeiro, 2018).

Lê-se no artigo $1^{\circ}$ da lei que normatiza e organiza o sistema de garantia de direitos da criança e do adolescente vítima ou testemunha de violência (Lei $\mathrm{n}^{\circ}$ 13.431, 2017, ênfase adicionada), que entrou em vigor em 2018:

Esta lei ... cria mecanismos para prevenir e coibir a violência, nos termos do art. 227 da Constituição Federal, da Convenção sobre os Direitos da Criança e seus protocolos adicionais, da Resolução n. 20/2005 do Conselho Econômico e Social das Nações Unidas e de outros diplomas internacionais, e estabelece medidas de assistência e proteção à criança e ao adolescente em situação de violência.

A citação acima mostra que o estabelecimento de mecanismos para prevenir e coibir a violência pressuposto na Lei 13.431/2017 baseia-se em uma série de fontes. Entre elas estão as diretrizes para atuação da justiça em casos envolvendo crianças ou adolescentes vítimas ou testemunhas de crime do Conselho Econômico e Social da Organização das Nações Unidas (2005), além de outros diplomas internacionais.

$\mathrm{Ou}$ seja, das fontes citadas no artigo $1^{\circ} \mathrm{da}$ Lei 13.431/2017, a única que está especificamente relacionada ao sistema judicial e à colheita de depoimento de crianças vítimas ou testemunhas de crime é a Resolução 20/2005. Contudo, a despeito da menção, aspectos importantes da resolução e de diferentes diplomas internacionais ou são ignorados ou são valorados na legislação brasileira de modo muito diferente do original. Esses aspectos dizem respeito às definições de vitimização secundária, revitimização, pessoa de apoio e de intermediário; e ao conjunto variado de possibilidades arquitetônicas e procedimentais para a colheita de depoimento judicial de crianças e adolescentes. Essas diferenças desenham papéis e expectativas distintos para aqueles que intervêm nesse cenário.

O que se constata na Lei 13.431/2017 é a uniformização e a exclusividade do modo como a colheita do depoimento deve ocorrer, o que leva a um empobrecimento de atribuições e possibilidades de atuação. Esse é um dos pontos de conflito entre os que são a favor de modo irrestrito do depoimento especial e 
aqueles que apontam problemas na sua concepção e execução. Não se quer dizer, contudo, que o problema indicado possa ser resolvido com a simples adequação legislativa. Verifica-se que mesmo em países com marcos legais mais próximos à Resolução 20/2005 há problemas na prática de colheita de depoimento de crianças e adolescentes. Eles vão do não funcionamento de equipamentos até o desalinhamento entre diretrizes e protocolos (Bala, Evans, \& Bala, 2011).

É inegável que boa parte das discordâncias no Brasil gira em torno do papel do intermediário, isto é, daquele que facilita a comunicação entre juiz e depoente, e de quem o deve exercer. Argumentos sobre a proteção do depoente, sobre a melhoria da qualidade da prova e sobre a garantia do devido processo legal são utilizados abundantemente em conjunto com o de incompetência dos atores jurídicos para intervir com crianças e adolescentes. A análise da Resolução 20/2005 permite retomar esses argumentos, deixando perceber que existem diferentes formas de resposta aos problemas e desafios que o depoimento de crianças e adolescentes apresenta. As diferentes formas assinaladas não são dedutíveis do decreto que regula a Lei 13.431/2017 (Decreto 9.603, 2018).

Os objetivos deste artigo são: a) avaliar a dissonância entre a Lei 13.431/2017 e a Resolução 20/2005 e suas consequências para o desenho de papéis dos profissionais envolvidos na colheita de depoimento judicial; e b) analisar as definições de vitimização secundária, revitimização, pessoa de apoio e intermediário.

Descrevem-se e comentam-se diferentes modos de colheita de depoimento, tais como os realizados no Canadá, EUA e Reino Unido, assinalando o alinhamento deles com a Resolução 20/2005 e outras diretrizes internacionais.

\section{Método}

Realizou-se pesquisa qualitativa, baseada em levantamento bibliográfico e documental, tendo por eixos a Lei 13.431/2017 e a Resolução 20/2005, tanto quanto os procedimentos e papéis profissionais neles previstos. A análise pautou-se na interpretação e comparação de ambas as legislações e de seus documentos auxiliares à luz do que se identificou na última como recomendações relativas à proteção e ao cuidado. Os documentos auxiliares estão associados à
Organização das Nações Unidas, percorrendo período que se inicia em 1989.

A investigação revelou práticas que fogem do lugar-comum da colheita de depoimento como vista no Brasil e alinhadas à Resolução 20/2005. A descrição e o comentário delas requereu o exame de fontes da psicologia e do direito, oriundas de bases científicas, normativas e jornalísticas, caracterizando a pesquisa como interdisciplinar.

A descrição das práticas teve por foco a Europa, com ênfase no Reino Unido, assim como o Canadá e os Estados Unidos. Essas práticas foram escolhidas devido ao seu alinhamento com a Resolução 20/2005, ao mesmo tempo que se mostraram distintas entre si, apontando para possibilidades múltiplas de execução de procedimentos de colheita de depoimento e dos papéis profissionais envolvidos nele.

A Lei $13.431 / 2017$ foi apreciada em conjunto com o decreto que a regulariza, com a nota técnica do Conselho Federal de Psicologia sobre o tema, a Recomendação 33/2010 do Conselho Nacional de Justiça e o Estatuto da Criança e do Adolescente. Nesse tópico, as fontes dividiram-se entre científicas e normativas, da psicologia e do direito.

Jones (2009) lembra que a abordagem interdisciplinar é relativa a "investigações que se baseiam criticamente em duas ou mais disciplinas e que levam a uma integração de insights" ${ }^{1}$ (p. 76). Japiassu (2006), por sua vez, frisa que: "Onde [o interdisciplinar] se realiza melhor é no terreno, quando a solução de um problema o impõe e quando especialistas de domínios diferentes se reúnem e se concertam para solucioná-lo, ou seja, para dar-lhe uma resposta prática" (p. 50).

\section{Discussão}

\section{Depoimento judicial: Entre a proteção e a busca da verdade}

A Lei 13.431/2017 prevê que o depoimento especial se paute no uso de protocolos. Deduz-se disso que se espera que a prática ocorra com base em rotinas formalizadas, passíveis de reprodução e inscritas em diretrizes e procedimentos ditados naquela legislação.

Um dos principais pontos de controvérsia acerca do depoimento judicial reside no testemunho propriamente dito e no modo de colhê-lo, valendo-se ou não

\footnotetext{
${ }^{1}$ As traduções foram realizadas pelos autores.
} 
de intermediários. A necessidade decantada no Brasil da importância imprescindível desses personagens que atuam na comunicação entre o juiz e o depoente e a insistência com que se alega a incompetência do ator jurídico, em contraposição à competência do outro, do especialista (psicólogo, assistente social, pedagogo etc.) para ouvir a criança, são os eixos em torno dos quais concepções acerca do depoimento especial ora se tangenciam, ora se afastam uma da outra.

A aposta de que existe verdade a ser alcançada no testemunho, na sempre reiterada ausência de quaisquer outras provas, fecunda o solo no qual germina a expectativa do que poderá ser revelado nas audiências judiciais, com o intermediário, os equipamentos de videogravação, os protocolos. No limite, a busca pela verdade real, motivo de disputas recorrentes, a título de justiça, não raras vezes acaba por fazer tábula rasa das necessidades da vítima, deixando nela marcas que são também signos de violência. Por esse ângulo, não causa estranheza afirmações de que a vítima não existe no âmbito da justiça criminal (Felman, 2014; Khaled Jr., 2013; Ramos \& Ligeiro, 2018).

O que se mostra como justificativa para a existência de um modo específico de tomada de depoimento de crianças e adolescentes é, por um lado, a proteção e o cuidado; por outro, a melhoria da qualidade da prova, a busca da verdade e a responsabilização. Todos esses motivos são entendidos a partir do aumento de condenações, guardado sob o teto do devido processo legal. Mas, de fato, qual dessas justificativas prevalece no que se realiza no Brasil?

Não é preciso recapitular que a implementação do depoimento especial foi precedida de batalha na qual instâncias judiciais invalidaram determinações do Conselho Federal de Psicologia e do Conselho Federal de Serviço Social que limitavam a participação dos respectivos profissionais nesse tipo de prática. A esse respeito, nota técnica do Conselho Federal de Psicologia (2018) analisa os impactos da Lei 13.431/2017 na atuação de psicólogos e recomenda respostas a eles.

O cenário acima não é exclusivo do Brasil, tendo ocorrido também na África do Sul, quando trabalhadores sociais se recusaram a oferecer o tipo de serviço indicado (Jonker \& Swanzen, 2007). Dentre os motivos da recusa, havia a constatação de que a criança continuava a ser impactada por longas audiências que demoravam a ser agendadas; o conflito de papéis profissionais; a sensação de que não se conseguia evitar a vitimização secundária; e a negligência quanto às intervenções de apoio posteriores à colheita do depoimento judicial (Jonker \& Swanzen, 2007). Alguns motivos citados mostram-se atuais, manifestando-se nas preocupações expressas no Brasil e no Reino Unido (Hill, 2011).

Desde pelo menos 1999 a Organização das Nações Unidas, com base em suas agências, dedica atenção ao depoimento judicial, em particular no que se refere aos cuidados com a vítima e a testemunha.

Não por acaso, lê-se no Handbook on Justice for Victims, publicado sob os auspícios do Centro Internacional para Prevenção ao Crime, que as vítimas deveriam, sempre que possível, estar acompanhadas na sala de audiências por pessoa de apoio, isto é, por alguém que lhes ofereceria suporte emocional para depor. O Handbook lista ainda outras sugestões, tais como o uso de victim impact statements e a permanência de familiares junto à vítima na sala de audiências. As sugestões contemplam aspectos arquitetônicos e de uso do espaço nos fóruns, de modo a atender às diferentes necessidades das vítimas ou testemunhas (United Nations Office on Drugs and Crime, 1999).

Os victim impact statements são declarações escritas ou orais elaboradas por vítimas de crimes, com suas próprias palavras, descrevendo como a situação de violência as afetou. Os cinquenta estados dos EUA permitem o uso desse tipo de documento em alguma fase do processo judicial, assim como Canadá e Austrália, países que também se valem desse dispositivo, que pode ser gravado (Coimbra, 2016). O objetivo dessas declarações é permitir às vítimas, durante o julgamento do caso, apresentar ao aparato judicial o dano subjetivo sofrido pela situação de violência experimentada.

Aspectos ditados pelo Handbook em 1999 estão expressos na Resolução 20/2005 do Conselho Econômico e Social das Nações Unidas, tais como a importância da pessoa de apoio e a atenção às necessidades da vítima ou testemunha. É importante lembrar que, antes da Lei 13.431/2017, o Conselho Nacional de Justiça (2010) traçou diretrizes para a realização de serviços voltados à colheita de depoimento de crianças e adolescentes no Brasil. Nelas se previa que os tribunais criariam serviços especializados para escutar crianças e adolescentes vítimas ou testemunhas de violência nos processos judiciais. É com essa recomendação que a implantação de serviços e a constituição de protocolos para essa finalidade passam a ocorrer de modo mais frequente. E quais são os pontos principais do documento? 


\section{O Conselho Nacional de Justiça e o equilíbrio na busca da verdade}

A Recomendação 33/2010 tem entre seus considerandos: a) o artigo 12 da Convenção Internacional sobre os Direitos da Criança, explicitando que ele assegura à criança e ao adolescente o direito de serem ouvidos em todo o processo judicial que possa afetar seu interesse; b) o artigo 28, parágrafo $1^{\circ}$, e $\mathrm{o}$ artigo 100, parágrafo único, inciso XII, do Estatuto da Criança e do Adolescente, que asseguram à criança e ao adolescente o direito de terem sua opinião considerada e de serem ouvidos previamente por equipe interprofissional; c) a atenção à produção de provas testemunhais e à qualidade das ações penais; d) a importância de equilibrar a busca da verdade, a responsabilização do autor e a preservação da criança e do adolescente.

É importante esclarecer pontos-chave dos considerandos da recomendação, sobretudo quanto aos dois primeiros listados. $\mathrm{O}$ artigo 12 da Convenção Internacional sobre os Direitos da Criança é dividido em dois itens, embora raramente se dê atenção ao segundo deles. O primeiro diz que os "Estados Partes devem assegurar à criança que é capaz de formular seus próprios pontos de vista o direito de expressar suas opiniões livremente sobre todos os assuntos relacionados a ela ..." (Resolução 44/25, 1989, art. 12, 1). O segundo expressa de que modo a criança formularia seus próprios pontos de vista: “. . . quer diretamente quer por intermédio de um representante ou órgão apropriado, em conformidade com as regras processuais de legislação nacional" (Resolução 44/25, 1989, art. 12, 2, grifos nossos).

O sentido do artigo 12 é claro: expressar os pontos de vista diretamente é a primeira opção; expressar pela via de um intermediário, a segunda. No Brasil, associa-se o uso de intermediário à proteção, como se o depoimento direto não devesse, ele mesmo, ter seus mecanismos de proteção.

$\mathrm{O}$ Handbook of the Convention on the Rights of the Child enfatiza que a interpretação da Convenção deve levar em conta que os Estados decidam como a criança é ouvida; que o ponto de vista dela seja transmitido; que se adaptem salas de audiência e roupa dos juízes, apontando para maior informalidade; que se utilize videogravação, telas (biombos), salas especiais, sala de espera e preparação da criança para o depoimento (United Nations Children's Fund, 2007).

$\mathrm{O}$ segundo item da recomendação merece atenção. $\mathrm{O}$ artigo 28 , parágrafo $1^{\circ}$, do Estatuto da
Criança e do Adolescente especifica que os menores de 18 anos, sempre que possível, serão ouvidos previamente por equipe interprofissional no que se refere aos processos de colocação em família substituta (guarda, tutela ou adoção). Isto é, nada ali tem relação com a função de intermediário existente na prática de depoimento especial no Brasil. O que está descrito não se refere à audiência propriamente dita. O artigo 100, parágrafo único, inciso XII, da mesma legislação, aponta que, quanto à aplicação de medidas de proteção, é obrigatória a oitiva e a participação da criança e do adolescente. Para tanto, eles devem ser ouvidos "em separado ou na companhia dos pais, de responsável ou de pessoa por si indicada ..." (Lei n. 8.069, 1990, grifos nossos).

Assim, há uma nítida equivalência entre o que se apresenta no Estatuto da Criança e do Adolescente e o que está apontado no Handbook on Justice for Victims. No entanto, não há, em geral, informação acerca desse uso nas práticas de depoimento especial no Brasil e isso não é objeto de comentário. Comparando-se os protocolos em uso no estado do Rio de Janeiro e em São Paulo, o segundo prevê a possibilidade de um acompanhante para o depoente; o primeiro, não (Santos \& Coimbra, 2017).

Analisando-se os artigos da Recomendação $33 / 2010$, verifica-se que o depoimento especial será gravado, valendo-se de sala especial, separada da sala de audiências, com a participação de profissional especializado. A recomendação define que os participantes deverão ser capacitados com base nos princípios da entrevista cognitiva. Observa-se que não é definido qual profissional será o responsável pela realização do depoimento especial, mas sim que deve haver capacitação nos princípios da entrevista cognitiva.

Stein (2015) ensina que o conjunto de técnicas denominado entrevista cognitiva foi desenvolvido a partir da constatação de que profissionais da segurança pública e do direito cometiam erros que poderiam afetar o testemunho. Dessa forma, tratou-se de preparar aqueles profissionais, estabelecendo-se parâmetros de atuação. Na origem, a entrevista cognitiva foi desenvolvida por psicólogos para ser executada sobretudo por atores do campo da segurança pública e justiça. Ela não é o único instrumento existente para tal finalidade, segundo Stein. A pesquisadora esclarece que a entrevista cognitiva é uma das técnicas de entrevista investigativa. Um exemplo de protocolo de entrevista investigativa com crianças é 
o do National Institute of Child Health and Human Development (NICHD). A condução da entrevista investigativa pressupõe a capacitação do entrevistador e o registro da entrevista. O objetivo do procedimento é obter testemunho confiável e detalhado. Pressupõe-se que a idade e o desenvolvimento da criança sejam variáveis importantes a serem considerados na entrevista investigativa (Office of Juvenile Justice and Delinquency Prevention, 2015).

A recomendação especifica ainda que "os serviços técnicos do sistema de justiça devem estar aptos a promover apoio, orientação e encaminhamento de assistência à saúde física e emocional da vítima ou testemunha e seus familiares, quando necessários, durante e após o procedimento judicial" (Recomendação 33, 2010, inciso IV, grifos nossos). Essa é a única menção no documento que segue a nomenclatura do Estatuto da Criança e do Adolescente, com os diferentes nomes de equipe interprofissional, especializada, multidisciplinar, técnica, interprofissional. Não é possível deduzir da recomendação que a priori os integrantes da equipe seriam responsáveis pela intermediação do testemunho, mas, sim, que eles teriam o seu lugar no cuidado expresso na forma de apoio, orientação e encaminhamento.

A Recomendação 33/2010 aponta a necessidade de que exista controle relativo ao tempo de tramitação processual, de modo que não haja lapso significativo entre o conhecimento do fato investigado e a audiência de depoimento especial. Como se verá, esse ponto é de máxima importância nos diferentes procedimentos relativos ao depoimento de crianças e adolescentes, ainda que sua realização não seja unívoca.

\section{O depoimento especial e o Conselho Econômico e Social das Nações Unidas}

A Lei 13.431/2017 especifica o modo pelo qual o depoimento especial deve ocorrer, definindo outra modalidade de abordagem, denominada escuta especializada. Esta é caracterizada por ser entrevista realizada em órgão de proteção, com a menção de que o relato deva estar limitado ao necessário para o cumprimento do que é previsto nessa etapa (Lei n. 13.431, 2017, art. $7^{\circ}$ ). O depoimento especial, diferentemente, ocorre perante autoridade policial ou judicial (Lei no 13.431, 2017, art. 8). Não há informações sobre os efeitos dessa distinção, muito menos como ocorre a relação entre um momento e outro, assim como suas dificuldades ou benefícios. Tanto a escuta quanto o depoimento são modos de produção de prova, segundo Digiácomo e Digiácomo (2018), o que marca entendimento diverso daquele descrito no Decreto 9.603/2018 e previsto pelo Conselho Federal de Psicologia (2018).

No artigo $1^{\circ}$ da Lei n. 13.431 (2017) são listadas as fontes que a embasam. O que chama a atenção é que, de todas elas, apenas uma se refere especificamente à colheita de depoimento de crianças e adolescentes: a Resolução 20/2005, do Conselho Econômico e Social das Nações Unidas (2005). É exatamente esse documento anunciado que não tem presença efetiva na Lei $13.431 / 17$. De fato, chega-se ao extremo de se valorizar na legislação nacional aspectos que são secundários na Resolução 20/2005, ignorando outros originalmente relevantes.

A Lei no 13.431 (2017) prevê em seu artigo 11 que a prática da colheita de depoimentos de crianças e de adolescentes seja regida por protocolos, tendo por alvo reduzir o depoimento propriamente dito a uma só vez. Não é claro se esse objetivo é alcançável nos termos do sistema processual penal brasileiro ou quantas vezes em média crianças e adolescentes são ouvidas de fato no Brasil atualmente nos diferentes modos pelos quais o depoimento especial está funcionando.

No Simpósio sobre a Prática do Depoimento Especial: Repercussões da Lei 13.431/2017, realizado pela Corregedoria Geral da Justiça do Rio de Janeiro, em junho de 2018, foi comentado por um representante do Ministério Público que é provável que o número de vezes que o depoente será ouvido gire em torno de três, ao menos nesse estado brasileiro. Ainda sobre a repetição de depoimentos, vale manter em perspectiva que o artigo 11 , parágrafo $2^{\circ}$, da Lei n. 13.431 (2017, grifos nossos) expressa que "Não será admitida a tomada de novo depoimento especial, salvo quando justificada a sua imprescindibilidade pela autoridade competente $e$ houver $a$ concordância da vítima ou da testemunha, ou de seu representante legal". Assim, formalmente a criança ou o adolescente e sua família decidiriam quanto à possibilidade de repetição da colheita de depoimento.

Do mesmo modo, a lei não atribui a realização do depoimento especial à equipe multiprofissional, mas a "profissionais especializados". Ela determina a existência de sala especial e a transmissão do depoimento para a sala de audiências, com sua gravação em áudio e vídeo, permitindo que o profissional especializado adapte as perguntas à compreensão da criança ou do 
adolescente. Logo, ele desempenha papel ativo no procedimento, com ampla margem de controle sobre como proceder, no entendimento de Digiácomo e Digiácomo (2018), o que é sustentado pelo Decreto n. 9.603 (2018). Esse grau de liberdade mostrou-se problemático na experiência sul-africana, ao menos em certo período de existência de serviços voltados a testemunhas crianças e adolescentes, conforme Jonker e Swanzen (2007).

A legislação garante que se testemunhe diretamente ao juiz, se assim se preferir. A Convenção Internacional dos Direitos da Criança oferece primazia a essa possibilidade. No caso brasileiro, pelo contrário, desconhece-se como essa alternativa é oferecida ao depoente e a sua família, ou mesmo que dispositivos de proteção seriam utilizados nessa circunstância. De modo geral, esse tema não é tratado nas abordagens acerca do depoimento especial e nas discussões que o acompanham.

Cabe dizer que as sugestões e recomendações oriundas do I Encontro Nacional de Experiências de Tomada de Depoimento, realizado em Brasília, em 2011, apontavam diretamente para a necessidade de formar juízes, promotores de justiça e defensores públicos para participar da colheita do depoimento especial e para proceder à entrevista de crianças e adolescentes vitimizados que manifestam interesse em depor diretamente ao magistrado (Coimbra, 2014). Talvez se possa reconhecer nesses enunciados o despreparo dos atores jurídicos para a realização do empreendimento. Ao mesmo tempo, eles sublinham a importância da formação e do treinamento de tais profissionais para cumprir a contento a responsabilidade que lhes é creditada e estabelecida no que agora é lei.

A Lei 13.431 (2017) prevê ainda celeridade no atendimento após a revelação da violência por parte de representantes da saúde, assistência social e justiça (artigo 14, parágrafo $1^{\circ}$, inciso V). Ela determina em seu artigo $4^{\circ}$, inciso IV, parágrafo $2^{\circ}$, que "Os órgãos de saúde, assistência social, educação, segurança pública e justiça adotarão os procedimentos necessários por ocasião da revelação espontânea da violência”. Não há esclarecimentos sobre que procedimentos ligarão um e outro órgão nesses casos, o que pode levar à redundância de ações.

A Resolução 20/2005 firma diretrizes para a justiça em casos envolvendo crianças vítimas ou testemunhas de crimes. Ela se caracteriza por reunir procedimentos com o objetivo de prevenir a vitimização. Assim, o documento adverte aos seus destinatários que as interferências na vida privada devem ser limitadas ao mínimo necessário. Ele aponta que a colheita de evidências deve assegurar resultados justos e equitativos no processo judicial: entrevistas, exames e outras formas de investigação precisam ser conduzidos por profissionais treinados. A resolução ressalta que a idade não será impeditivo para que a criança participe do processo judicial que the concerne. Ela se coaduna com o previsto no artigo 12 da Convenção, e que é explicitado em partes diferentes do documento: “. . . toda criança deve ser tratada como uma testemunha capaz, com ou sem auxílio à comunicação e outras formas de assistência" (Conselho Econômico e Social da Organização das Nações Unidas, 2005, inciso VI, 18, grifos nossos).

A resolução lista algumas medidas que tornariam mais fácil para crianças e adolescentes as fases de pré-julgamento e julgamento. Duas dessas medidas são: valer-se de especialistas, a fim de atender as necessidades deles; e utilizar pessoas de apoio, sejam elas especialistas ou familiares, para acompanhar a criança ou o adolescente antes, durante e após o depoimento.

O documento aponta ainda que devem ser utilizados: salas e ambientes adequados; recessos durante o depoimento; audiências agendadas conforme a necessidade da criança; notificações para que a criança compareça ao fórum apenas quando necessário; e serviços interdisciplinares para vítimas infantis. Ele recomenda evitar, se possível, que o suposto autor interrogue o depoente; que se utilizem meios de apoio ao testemunho; e a nomeação de peritos psicólogos.

Constata-se que não há menção explícita ao intermediário na resolução, distinto do que ocorre quanto à pessoa de apoio. Isso é reforçado quando se estuda o Handbook for Professionals and Policymakers (United Nations Office on Drugs and Crime, 2009a). Trata-se de documento elaborado para colaborar na efetivação da Resolução 20/2005. Nele a pessoa de apoio (support person) é citada quarenta vezes, enquanto o intermediário (intermediary) é citado dez vezes.

\section{Pessoa de apoio e intermediário}

O Handbook apresenta a pessoa de apoio como especialista ou familiar que tem por atribuição acompanhar a criança durante o testemunho. O objetivo é prover apoio emocional, reduzindo o impacto que o ambiente judicial possa ter sobre o depoente. $\mathrm{O}$ documento ressalta que se trata de recurso válido, independentemente do sistema processual criminal vigente. 
A pessoa de apoio está proibida de interferir no depoimento da criança, devendo, se permitido, apenas permanecer junto a ela ao longo do depoimento.

O Estatuto da Criança e do Adolescente apresenta papel semelhante ao da pessoa de apoio, ainda que não nomeado dessa forma, como visto. A Lei n. 13.431 (2017, grifos nossos) também aparenta sugerir algo como a pessoa de apoio em seu artigo $5^{\circ}$, inciso XI, em termos de garantia de direitos da criança ou do adolescente: “. . . ser assistido por profissional capacitado e conhecer os profissionais que participam dos procedimentos de escuta especializada e depoimento especial". Ora, segundo esse enunciado, o profissional capacitado deve assistir a criança ou o adolescente, não equivalendo aos profissionais que participam dos procedimentos de escuta especializada e depoimento especial. Trata-se de dois papéis diferentes. Não seria possível interpretar a assistência a ser prestada como associada ao que realiza a pessoa de apoio? Entretanto, em que pese a menção a papel análogo ao da pessoa de apoio no protocolo do Tribunal de Justiça de São Paulo (Santos \& Coimbra, 2017), ela não se reveste de qualquer relevância nas discussões sobre o depoimento especial no Brasil.

O intermediário, por sua vez, é aquele que traduz a questão formulada na audiência para a criança ou adolescente. O Handbook deixa entender que essa tradução não é um recurso obrigatório, mas utilizado quando avaliado como necessário, podendo o intermediário realizar comentários acerca da resposta da criança.

O intermediário não é um especialista em memória e não define se o depoente tem condições de testemunhar; seu papel é tornar efetiva a comunicação entre os atores envolvidos na audiência. No Reino Unido, o intermediário pode estar presente na audiência sem necessariamente tomar parte da colheita de depoimento. Isso porque previamente ele poderá ter instruído o entrevistador sobre como proceder no caso concreto (Cooper \& Mattison, 2017; The Council of the Inns of Court, 2016). O relatório do intermediário é peça importante, pois se trata do documento que permitirá ao juiz decidir se há ou não necessidade da atuação daquele profissional na audiência (The Council of the Inns of Court, 2016).

Em outro documento, que tem por alvo a Resolução 20/2005, o Model Law and Related Commentary $^{2}$, há a mesma desproporção entre a pessoa de apoio, citada 78 vezes, e o intermediário, citado uma única vez (United Nations Office on Drugs and Crime, 2009b).

O Model Law tem por objetivo colaborar para que os Estados que compõem o sistema das Nações Unidas possam adaptar sua legislação às disposições apresentadas na Resolução 20/2005. Observa-se nesse documento que a sala especial, a partir da qual imagem e som são transmitidos em circuito fechado para a sala de audiências, não é a única forma protegida de colheita do testemunho. São descritos como possibilidades o uso de tela removível (cortina ou biombo) e a retirada do acusado da sala de audiências.

O Model Law define tanto a pessoa de apoio quanto o intermediário nos moldes já indicados. A pessoa de apoio pode acompanhar a criança desde a fase de investigação; indicar terapia ou aconselhamento; prestar informações sobre o processo judicial à criança e seus responsáveis; e elaborar com o advogado da criança as diferentes opções relativas à apresentação de provas e medidas de proteção e assistência, de modo que a relação de confiança entre a criança e a pessoa de apoio é fundamental (Coimbra, 2014; McAuliff, Lapin, \& Michel, 2015; United Nations Office on Drugs and Crime, 2009b).

O intermediário, no Model Law, é circunscrito à colaboração do testemunho da criança, atuando como intérprete quando isso se fizer necessário (Coimbra, 2014; United Nations Office on Drugs and Crime, 2009b). No Reino Unido o intermediário não se confunde com o intérprete quanto à atuação com aqueles que não têm familiaridade com a língua inglesa (The Council of the Inns of Court, 2016).

\section{Revitimização, vitimização secundária}

O Model Law define vitimização secundária apoiando-se no Handbook on Justice for Victims. Em síntese, trata-se de vitimização que decorre da resposta de instituições e indivíduos e não do agente que originalmente teria sido o autor da violência. Uma das táticas adotadas para evitar a vitimização secundária é não repetir procedimentos durante o processo judicial (United Nations Office on Drugs and Crime, 2009b). Existe ampla bibliografia relativa à vitimização secundária, tal como levantada por Piñeres Botero, Coronel e Pérez (2009).

${ }^{2}$ Tradução disponível em: https://zenodo.org/record/1485616. 
A vitimização secundária pode decorrer das dificuldades de equilibrar os direitos da vítima com os direitos do acusado, sobretudo ao não se levar em conta a perspectiva da primeira. A atenção à vítima implica a avaliação de suas necessidades e da viabilidade de recursos para contemplá-las (Roque, Ferriani, Gomes, Silva, \& Carlos, 2014; United Nations Office on Drugs and Crime, 1999).

A definição de revitimização do Model Law apoia-se em prescrições do Conselho da Europa (2006). Nelas, o termo utilizado é vitimização repetida (repeat victimisation), definida como sofrer mais de um incidente criminal ao longo de período específico. O Conselho da Europa é órgão da União Europeia que atua em defesa dos direitos humanos, da democracia e da estabilidade político-social no continente (Lanzarote Committee, 2017).

A distinção entre revitimização e vitimização secundária foi mais uma vez afirmada no documento Terminology Guidelines for the Protection of Children from Sexual Exploitation and Sexual Abuse, também denominado Luxembourg Guidelines. Ele é o resultado do trabalho realizado pelo Interagency Working Group on Sexual Exploitation of Children, ligado ao Alto Comissariado das Nações Unidas para os Direitos Humanos (Greijer \& Doek, 2016).

O ponto de partida do documento é o de que as diretrizes linguísticas se constituem como ferramenta-chave no combate ao abuso sexual infantil. Ele apresenta definições e desambiguações elaboradas pelo grupo, cujo trabalho envolveu diferentes agências que trabalham com o tema.

As Luxembourg Guidelines definem a vitimização secundária como a que decorre de atitudes, comportamentos e práticas que resultam em dano adicional à vítima. A vitimização secundária deriva de ação indevida e incorreta de serviços que deveriam proteger a criança e o adolescente, tanto quanto de reação social negativa à vitimização primária. Ela é o resultado de respostas erradas às necessidades das vítimas, produto de inquirições repetidas e redundância de procedimentos ao longo do processo judicial.

A revitimização ou vitimização repetida é consequência de ação danosa subsequente ao primeiro episódio, realizada por diferente ofensor. As Luxembourg Guidelines enfaticamente recomendam que vitimização secundária e revitimização sejam diferenciados (Greijer \& Doek, 2016). Outra definição a se destacar no documento é a de vitimização colateral ou indireta. Trata-se daquela na qual outras pessoas, próximas à vítima ou ao agressor, podem sentir-se vitimizadas. Ela guarda equivalência com a definição de vulnerabilidade indireta, apresentada no artigo 19, II, da Lei 13.431/2017, ao passo que o Handbook on Justice for Victims menciona algo do mesmo gênero (United Nations Office on Drugs and Crime, 1999).

$\mathrm{O}$ que se tem feito em outros países quanto às intervenções voltadas para o cuidado e a responsabilização em situações de suspeita de violência contra criança e adolescente, em particular de natureza sexual? Podem-se identificar nelas elementos que evidenciem alinhamento com a Resolução 20/2005?

\section{Práticas internacionais de colheita de depoimento judicial}

Uma cartografia do campo de práticas de colheita de depoimento judicial de crianças e adolescentes ao longo do planeta foi realizada por Santos e Gonçalves (2008). No entanto, a variedade de intervenções ampliou-se ao longo do tempo. Em alguns casos, a figura do intermediário é secundária ou mesmo inexistente, não sendo necessário que um profissional específico desempenhe esse papel (Coimbra, 2014; Santos \& Coimbra, 2017).

Deve ser sublinhado que o depoimento judicial de crianças e adolescentes conta com ampla visibilidade no exterior, sendo objeto de matérias jornalísticas recorrentes ${ }^{3}$. Ela advém do aumento de participações de crianças em audiências e da constatação de que há falhas graves nos procedimentos adotados. Parte dessas falhas foi resumida pelo jornal britânico The Guardian: "as crianças enfrentam problemas significativos quando testemunham em juízo. O problema-chave... é a falta de apoio consistente, de efetivo gerenciamento das fases de pré-julgamento e julgamento propriamente dito, bem como do controle de questionamentos desleais" (Hill, 2011a).

Quanto às diferentes práticas realizadas, é inegável o avanço do uso de cães treinados que acompanham os depoentes ao longo de procedimentos judiciais. A relação do depoente com o cão antecede a audiência e se prolonga para além dela. Esse recurso

${ }^{3}$ Ver as seguintes matérias do jornal The Guardian, publicadas entre 2011 e 2018: Williams (2018); Wahlquist (2017); Hernandez (2013); e Hill (2011a, 2011b). 
é utilizado em diferentes partes do Canadá e dos EUA. O objetivo principal é reduzir o grau de estresse, criando um ambiente relativamente confortável e, em tese, menos danoso durante a colheita do depoimento. Outros recursos podem ser acionados concomitantemente, como a pessoa de apoio (Holder, 2013).

No Canadá, em particular na província de Ontário, além do uso de cães treinados, outros serviços são oferecidos aos depoentes pela London Family Court Clinic. Nesses casos, há distintos modos de o depoimento ser colhido: a sala especial não é a única opção, havendo alternativas simples, como o uso de biombos, tal como prescrito na Resolução 20/2005, de modo que a decisão sobre como o depoimento será colhido seja do juiz (Coimbra, 2014; Santos \& Coimbra, 2017).

O pressuposto das intervenções realizadas é de que o preparo e o apoio contribuem para minorar a probabilidade de haver trauma devido à experiência de testemunhar (Bala, Evans \& Bala, 2011). A pessoa de apoio e a atenção concedida ao acompanhamento pré-audiência são elementos cruciais nas intervenções realizadas e têm por alvo evitar a vitimização secundária, mantendo-se as garantias do devido processo legal. Não há intermediário na prática levada a cabo em Ontário (Coimbra, 2014; Santos \& Coimbra, 2017).

Na Europa, observa-se outro exemplo de intervenção em casos de suspeita de violência contra crianças e adolescentes, em particular, de violência sexual. Trata-se da Barnahus (Casa da Criança). Essa proposta de trabalho teve início em 1998 na Islândia, apoiando-se em práticas realizadas nos EUA, nos Child Advocacy Centers, desde a década de 1980. Hoje é modelo incentivado pelo Conselho da Europa (Lanzarote Committee, 2017; 2018).

A Barnahus é um centro interdisciplinar e multiagência para crianças vítimas e testemunhas. Os procedimentos realizados compreendem entrevistas de investigação observadas por meio de circuito fechado de TV por um conjunto de profissionais: policiais, agentes de proteção à infância, promotor de justiça, advogado de defesa, juiz e representante legal da criança. Utilizam-se os princípios da entrevista forense, realizada o mais rapidamente possível em face do suposto fato ocorrido (Johansson, Stefansen, Bakketeig, \& Kaldal, 2017; O'Donnell \& Wenke, 2017).

A Barnahus não funciona exatamente nos mesmos moldes em todos os países em que é utilizada, não substituindo outros modos de atuação. No entanto, observa-se em alguns exemplos tanto o uso da pessoa de apoio quanto o de policiais treinados como entrevistadores forenses. Em alguns casos, faz-se distinção entre entrevista exploratória (exploratory interview), quando não se tem a explicitação do suposto fato relacionado à violência, e entrevista investigativa (investigative interview), quando essa explicitação terá ocorrido. Por vezes, a primeira é realizada por profissionais da área social e a segunda por policiais (Johansson, Stefansen, Bakketeig, \& Kaldal, 2017;;O'Donnell \& Wenke, 2017).

A Inglaterra é apontada por Furniss (1992) como referência positiva em práticas relacionadas à intervenção em casos de violência sexual contra crianças e adolescentes (Coimbra, 2018). Bala, Evans e Bala (2011) apontam para o mesmo país, indicando que as reformas realizadas ou propostas ali devem ser cuidadosamente estudadas. Essas práticas e diretrizes estão consolidadas no Achieving Best Evidence in Criminal Proceedings: Guidance on Interviewing Victims and Witnesses, and Guidance on Using Special Measures (Smith, 2011).

O Achieving Best Evidence apresenta definições e orientações que se alinham àquelas oriundas da Resolução 20/2005 e de seus documentos acessórios. Ele é divulgado pelo The Crown Prosecution Service, principal órgão de acusação em processos criminais na Inglaterra e no País de Gales e é assinado por representantes do Ministério da Justiça e outros ligados à assistência social e à infância. O documento enfatiza a importância do planejamento e da preparação da criança e do adolescente para as entrevistas, o que pode ocorrer imediatamente antes da audiência ou durar tempo indeterminado; o cuidado em definir conceitos e noções; o estabelecimento de um sistema de avaliação consistente; a responsabilidade dos entrevistadores quanto a garantir que o depoente esteja participando livremente do procedimento; o uso da pessoa de apoio, denominada court witness supporter; e a eventual utilização do victim impact statement, denominado victim personal statement (Smith, 2011).

Destaca-se no percurso realizado a dissonância entre a Lei 13.431/2017 e a Resolução 20/2005, citada pela primeira como uma de suas fontes. Essa dissonância tem por desdobramento, no Brasil, o desenho limitado de papéis e intervenções relativos a crianças e adolescentes vítimas ou testemunhas de crime. 
As definições de vitimização secundária, revitimização, pessoa de apoio e intermediário foram comentadas, constatando-se como elas colaboram para a concepção de ações previstas nas diretrizes internacionais. As práticas estrangeiras descritas mostram-se alinhadas à Resolução 20/2005, apontando a proeminência do cuidado e atenção ao depoente, sem desconsiderar a busca de efetividade na produção de provas.

\section{Considerações finais}

A dissonância entre a Resolução 20/2005 e a Lei 13.431/2017 expressa as dificuldades na discussão e avaliação sobre diferentes formas de realizar a colheita de depoimento de crianças e adolescentes vítimas ou testemunhas de crime. Isso acaba por configurar um quadro no qual se tende a crer que a forma determinada no Brasil conteria em si os melhores procedimentos cabíveis, impedindo a exploração de novas possibilidades no campo.

A Lei 13.431/2017, ao se referir à Resolução 20/2005, insinua um alinhamento que não se confirma, tal como mostrado neste artigo. Esse mesmo problema existe quanto às reiteradas menções ao artigo 12 da Convenção Internacional dos Direitos da Criança. Em geral, a interpretação dele ocorre de modo excessivamente parcial e incompleto, ignorando-se os sentidos que advêm da leitura extensa dos itens que o compõem. O não alinhamento e a interpretação incompleta levam a proposições de atuações que ficam aquém das necessidades das crianças e dos adolescentes que testemunham.
A legislação e os comentários sobre o depoimento especial, grosso modo, ignoram os conceitos de vitimização secundária, revitimização, pessoa de apoio, intermediário, victim impact statements. Parte importante do embate do depoimento especial centra-se na figura do intermediário, desconhecendo-se seus limites e suas distintas formas de atuação no estrangeiro. A pessoa de apoio, onipresente nas normas e nos exemplos de práticas utilizados neste artigo, está relegada à sombra no Brasil. A falta de destaque do conceito de vitimização secundária inibe a atenção a ser concedida aos danos que práticas e atitudes, a título de proteção, podem produzir, mesmo se conduzidos por especialistas. Não se trata apenas de evitar repetições.

Ainda que o depoimento especial tenha sido adotado por todo o país, são escassos os dados que permitem avaliar sua eficiência, eficácia e efetividade. Certamente tal avaliação não pode ser realizada apenas com base no aumento do número de condenações ou de depoimentos realizados. A demora na realização das audiências, a negligência quanto ao apoio antes, durante e após o depoimento, o tempo de tramitação processual e o número de vezes em que se colhe o depoimento são indicadores básicos que precisam ser medidos, geridos e tornados públicos. A pesquisa empírica e teórica em torno das noções e conceitos mencionados ainda exige investimento, a fim de que se possam desenhar papéis e formas de atuação em que o cuidado e a reparação possam ter seu lugar assegurado em um cenário mais bem conhecido por todos.

\section{Referências}

Bala, N., Evans, A., \& Bala, E. (2011). Hearing the voices of children in Canada's criminal justice system: Recognising capacity and facilitating testimony. Child and Family Law Quarterly, 22(1), 21-45.

Brito, L., \& Pereira, J. (2012). Depoimento de crianças: Um divisor de águas nos processos judiciais? Psico-USF, 17(2), 285-293. https://doi.org/10.1590/S1413-82712012000200012

Coimbra, J. (2014). Depoimento especial de crianças: Um lugar entre proteção e responsabilização? Psicologia: Ciência e Profissão, 34(2), 362-375. https://doi.org/10.1590/1982-3703000732013

Coimbra, J. (2016, 1 de novembro). Victim impact statements: Oque éisso? Palavras em transe. http://bit.ly/2q23B23

Coimbra, J. (2018, 29 de setembro). Resumo do Curso de Tilman Furniss "Enfrentamento do abuso sexual na criança e no adolescente". https://zenodo.org/record/1439058

Conselho Econômico e Social da Organização das Nações Unidas. (2005). ECOSOC Resolution 2005/20. Guidelines on Justice in Matters involving Child Victims and Witnesses of Crime. http://bit.ly/2qzbu2l

Conselho Federal de Psicologia. (2018). Nota Técnica n. 1/2018/GTEC/CG. Nota técnica sobre os impactos da Lei n. 13.431/2017 na atuação das psicólogas e dos psicólogos. CFP. http://bit.ly/2CAoqtr 
Conselho Nacional de Justiça. (2010). Recomendação n. 33, de 23 de novembro de 2010. Recomenda aos tribunais a criação de serviços especializados para escuta de crianças e adolescentes vítimas ou testemunhas de violência nos processos judiciais. http://bit.ly/2Dwd4dF

Cooper, P., \& Mattison, M. (2017). Intermediaries, vulnerable people and the quality of evidence. The International Journal of Evidence \& Proof, 21(4), 351-370. http://doi.org/10.1177/1365712717725534

Conselho da Europa. (2006). Recommendation Rec 8 of the Committee of Ministers to member states on assistance to crime victims. http://bit.ly/2Qy8ukW

Decreto n. 9.603, de 10 de dezembro de 2018. (2018). Regulamenta a Lei n. 13.431, de 4 de abril de 2017, que estabelece o sistema de garantia de direitos da criança e do adolescente vítima ou testemunha de violência. https://bit.ly/3wdn4il

Digiácomo, M., \& Digiácomo, E. (2018). Comentários à Lei n. 13.431/2017. Ministério Público do Estado do Paraná. http://bit.ly/2SAc7ns

Felman, S. (2014). O inconsciente jurídico: Julgamentos e traumas no século XX. Edipro.

Furniss, T. (1992). The multiprofessional handbook of child sexual abuse: Integrated management, therapy, and legal intervention. Routledge.

Greijer, S., \& Doek, J. (2016). Terminology guidelines for the protection of children from sexual exploitation and sexual abuse. ECPAT International. http://luxembourgguidelines.org/

Hernandez, D. (2013, 18 de fevereiro). Children prepare for their day in court: "They're being shown they have a voice". The Guardian. http://bit.ly/2Qp3Zcq

Hill, A. (2011a, 12 de maio). Children and the law: State failing to help young witnesses, says report. The Guardian. http://bit.ly/2QwmsEh

Hill, A. (2011b, 11 de maio). Child witness: "My evidence took two days. I hated every minute of it". The Guardian. http://bit.ly/2QpBCuR

Holder, C. (2013). All dogs go to court: The impact of court facility dogs as comfort for child witnesses on a defendant's right to a fair trial. Houston Law Review, 50(4), 1156-1187.

Japiassu, H. (2006). O sonho transdisciplinar e as razões da filosofia. Imago.

Johansson, S., Stefansen, K., Bakketeig, E., \& Kaldal, A. (Eds.). (2017). Collaborating against child abuse: Exploring the Nordic Barnahus model. Springer. http://bit.ly/2O2fLs7

Jones, C. (2009). Interdisciplinary approach: Advantages, disadvantages, and the future benefits of interdisciplinary studies. Essai, 7(1), 76-81.

Jonker, G., \& Swanzen, R. (2007). Serviços de intermediação para crianças-testemunhas que depõem em tribunais criminais da África do Sul. Sur: Revista Internacional de Direitos Humanos, 4(6), 94-119. https://doi.org/10.1590/ S1806-64452007000100006

Khaled Jr., S. (2013). A busca da verdade no processo penal: Para além da ambição inquisitorial. Atlas.

Lanzarote Committee. (2017). Protection of children against sexual abuse in the circle of trust: The framework. Council of Europe. http://bit.ly/2DoGsCr

Lanzarote Committee. (2018). Protection of children against sexual abuse in the circle of trust: The strategies. Council of Europe. http://bit.ly/2Drjb2V

Lei $n$. 13.431, de 4 de abril de 2017. (2017). Estabelece o sistema de garantia de direitos da criança e do adolescente vítima ou testemunha de violência e altera a Lei no 8.069, de 13 de julho de 1990 (Estatuto da Criança e do Adolescente). https://bit.ly/3AxxLz0

Lei n. 8.069, de 13 de julho de 1990. (1990). Dispõe sobre o Estatuto da Criança e do Adolescente e dá outras providências. https://bit.ly/2Tw5Y1A

McAuliff, B., Lapin, J., \& Michel, S. (2015). Support person presence and child victim testimony: Believe it or not. Behavioral Sciences \& the Law, 33(4), 508-527. http://doi.org/10.1002/bsl.2190

O'Donnell, R., \&Wenke, D. (2017). Barnahus quality standards summary. Council of the Baltic Sea States Secretariat and Child Circle. http://bit.ly/2NA04Z4 
Office of Juvenile Justice and Delinquency Prevention. (2015). Child forensic interviewing: best practices (pp. 1-20). U.S. Department of Justice. http://bit.ly/2zTbi2m

Pelisoli, C., \& Dell'Aglio, D. (2016). A humanização do Sistema de Justiça por meio do depoimento especial: experiências e desafios. Psico-USF, 21(2), 409-421. https://doi.org/10.1590/1413-82712016210216

Pelisoli, C., Dobke, V., \& Dell'Aglio, D. (2014). Depoimento especial: Para além do embate e pela proteção das crianças e adolescentes vítimas de violência sexual. Temas em Psicologia, 22(1), 25-38. https://doi.org/10.9788/TP2014.1-03

Piñeres Botero, C., Coronel, E., \& Pérez, C. (2009). Revisión teórica del concepto de victimización secundaria. Liberabit, 15(1), 49-58. http://bit.ly/2ELo5qm

Ramos, S. (2015). Depoimento Especial de crianças: Multiversos em cena [Tese de doutorado, Universidade Federal do Rio de Janeiro]. Conselho Federal de Psicologia. http://bit.ly/2DyAcly

Ramos, S., \& Ligeiro, H. (2018, 13 de junho). (H)ouve? [Vídeo]. YouTube. http://bit.ly/2EOVwt6

Resolução 44/25, de 20 de novembro de 1989. (1989). Convenção sobre os direitos da criança. Assembleia Geral das Nações Unidas. https://uni.cf/2UtLpD6

Roque, E., Ferriani, M., Gomes, R., Silva, L., \& Carlos, D. (2014). Sistemas de justiça e a vitimização secundária de crianças e ou adolescentes acometidas de violência sexual intrafamiliar. Saúde e Sociedade, 23(3), 801-813. https:// doi.org/10.1590/S0104-12902014000300006

Santos, A., \& Coimbra, J. (2017). O depoimento judicial de crianças e adolescentes entre apoio e inquirição. Psicologia: Ciência e Profissão, 37(3), 595-607. https://doi.org/10.1590/1982-3703004032016

Santos, B., \& Gonçalves, I. (2008). Depoimento sem medo (?): Culturas e práticas não-revitimizantes: Uma cartografia das experiências de tomada de depoimento especial de crianças e adolescentes. Presidência da República; Secretaria Especial dos Direitos Humanos; Childhood Brasil. http://bit.ly/2RLanat

Smith, C. (2011). Achieving best evidence in criminal proceedings: Guidance on interviewing victims and witnesses, and guidance on using special measures. United Kingdom, Ministry of Justice. http://bit.ly/2Svx0A9

Stein, L. (2015). Subsídios científicos em Psicologia do Testemunho. In Ministério da Justiça (Ed.), Avanços científicos em Psicologia do Testemunho aplicados ao reconhecimento pessoal e aos depoimentos forenses. Pensando o Direito (pp. 18-30). Ipea; Secretaria de Assuntos Legislativos. http://bit.ly/2QrRY1s

The Council of the Inns of Court. (2016). Intermediaries: Step by step. The Advocate's Gateway. http://bit.ly/2UYGoy8

United Nations Children's Fund. (2007). Implementation handbook for the Convention on the Rights of the Child. Unicef. https://uni.cf/2qXAkrB

United Nations Office on Drugs and Crime. (1999). Handbook on justice for victims: On the use and application of the Declaration of Basic Principles of Justice for Victims of Crime and Abuse of Power. UN ODCCP. http://bit.ly/2PIQjuP

United Nations Office on Drugs and Crime. (2009a). Justice in Matters involving Child Victims and Witnesses of Crime. Handbook for Professionals and Policymakers. United Nations. http://bit.ly/2NxtGGh

United Nations Office on Drugs and Crime. (2009b). Justice in matters involving child victims and witnesses of crime: Model law and related commentary. United Nations. http://bit.ly/2qz0msb

Wahlquist, C. (2017, 2 de agosto). Court system is unfair and traumatic for child sexual abuse victims. The Guardian. http://bit.ly/2QupMPS

Williams, R. (2018, 17 de fevereiro). Helping child witnesses: "One girl gave evidence with a hamster on her lap". The Guardian. http://bit.ly/2QrOfW1

\section{José César Coimbra}

Doutor em Memória social (Unirio), psicólogo no Poder Judiciário do Estado do Rio de Janeiro, professor no curso de Especialização em Psicologia Jurídica da Pontifícia Universidade Católica do Rio de Janeiro (CCE/PUC-Rio), Rio de Janeiro - RJ. Brasil.

E-mail: arcoim@yahoo.com.br

(1) https://orcid.org/0000-0002-8707-9756 


\section{Roberta Gomes Nunes}

Psicóloga no Poder Judiciário do Estado do Rio de Janeiro, instrutora da Escola de Administração Judiciária (ESAJ) e doutoranda em psicologia social na Universidade Estadual do Rio de Janeiro (UERJ), Rio de Janeiro - RJ. Brasil.

E-mail: robynunes@hotmail.com

(D) https://orcid.org/0000-0003-1545-6169

\section{Cristiana de Faria Cordeiro}

Juíza de direito do Tribunal de Justiça do Estado do Rio de Janeiro desde 1998. Atualmente é titular da Vara Criminal de Mesquita. Tutora do Curso EAD da ENFAM Depoimento Especial, de 2013 a 2018. Mestre em saúde e justiça pela Fundação Oswaldo Cruz (FioCruz), Rio de Janeiro - RJ. Brasil

E-mail: cristianafc@tjrj.jus.br

(i) https://orcid.org/0000-0003-2920-718X

Endereço para envio de correspondência:

Rua Filomena Nunes, 1071, sala 210, Olaria. CEP: 21021-380. Rio de Janeiro - RJ. Brasil.

Recebido 24/02/2019

Aceito 21/10/2020

Received 02/24/2019

Approved 10/21/2020

Recibido 24/02/2019

Aceptado 21/10/2020

Como citar: Coimbra, J. C., Nunes, R. G., \& Cordeiro, C. F. (2021). Depoimento especial, testemunho judicial, diretrizes internacionais: Dissonâncias. Psicologia: Ciência e Profissão, 41, 1-14. https://doi.org/10.1590/1982-3703003220412

How to cite: Coimbra, J. C., Nunes, R. G., \& Cordeiro, C. F. (2021). Special testimony, judicial testimony, international guidelines: Dissonances. Psicologia: Ciência e Profissão, 41, 1-14. https://doi.org/10.1590/1982-3703003220412

Cómo citar: Coimbra, J. C., Nunes, R. G., \& Cordeiro, C. F. (2021). Declaración especial, testimonio judicial, directrices internacionales: Disonancias. Psicologia: Ciência e Profissão, 41, 1-14. https://doi.org/10.1590/1982-3703003220412 